\title{
Crop production variability in North and South America forced by life-cycles of the EI Niño Southern Oscillation
}

\author{
Weston Anderson $^{1 *}$, Richard Seager ${ }^{1}$, Walter Baethgen ${ }^{2}$ and Mark Cane ${ }^{1}$ \\ 1. Lamont-Doherty Earth Observatory, Columbia University, Palisades, New York \\ 2. International Research Institute for Climate and Society, Palisades, New York \\ Lamont-Doherty Earth Observatory, 61 Route 9W, Palisades, NY 10964 \\ *weston@1deo.columbia.edu
}

\begin{abstract}
In this analysis we show how globally coherent teleconnections from life-cycles of the El Niño Southern Oscillation (ENSO) lead to correlated crop production anomalies in North and South America. We estimate the magnitude of ENSO-induced Pan-American production anomalies and discuss how increasing crop harvesting frequency may affect Pan-American production variability.
\end{abstract}

We find that ENSO accounts for $\sim 72 \%, 30 \%$ and $57 \%$ of Pan-American maize, soybean and wheat production variability, respectively. ENSO-induced production anomalies are greatest for maize, with median anomalies of $\sim 5 \%$ of Pan-American production. ENSO-induced yield anomalies for maize and soybeans tend to be of the same sign in North America and southeast South America but of an opposite sign in northeast Brazil. Teleconnections for wheat are more complicated because ENSO affects wheat yields via lagged soil moisture teleconnections in the US and an increased probability of disease in South America, but anomalies tend to be of the same sign in North America and southeast South America.

After broadly characterizing ENSO-induced production anomalies, we demonstrate that they are not static in time. Increasing crop harvesting frequency has affected the correlated risks posed by ENSO. We use a soil water balance to show that in Brazil changing to a safrinha 
cropping cycle increases both the mean water stress and the ENSO-induced soil water content anomalies during flowering in both the maize and soybean seasons, which is a result of increasing evaporative demand during times of lower precipitation and moving the flowering seasons into months with strong ENSO teleconnections. Increasing crop harvesting frequency in Brazil has therefore increased ENSO-induced production variability of soybeans and maize

Keywords: El Niño Southern Oscillation; ENSO; safrinha maize; America; soybean; teleconnection

\section{Introduction}

Global food crises are not driven by a single event, but rather result from a confluence of economic, political and natural factors. However, both the 2007-2008 and the 2010-2011 food crises were exacerbated by export restrictions in major crop producing countries following unexpected declines in the production of staple crops due to poor growing conditions (FAO, 2009; FAO, 2010). So while there is no single means of preventing such crises, understanding climate-driven crop production variability in major food producing nations is a start.

Estimating global-scale production variability attributable to climate requires that we quantify both the magnitude of anomalies within each production region and the correlation of anomalies between regions. While local crises may result from a poor harvest in a single country, globalscale crises are usually the result of multiple simultaneous crop failures. In this analysis we focus on how the El Niño Southern Oscillation (ENSO), which is a major driver of global patterns of temperature and precipitation (Trenberth et al., 1998; Alexander et al., 2002), affects PanAmerican wheat, soybean and maize production.

ENSO-induced risks to agriculture are correlated not only on large spatial scales, but also across multiple years. While past studies have looked at how ENSO teleconnections affect regionalscale yields in North and South America (Ferreyra et al., 2001; Podesta et al., 1999; Cunha 2001; Berlato and Fontana 2001; Lopez et al., 2003; Handler 1984; Phillips et al., 1999; Wannebo et al., 2003; Izaurralde et al., 1999; Mauget and Upchurch 1999; Hsieh et al., 1999), and global crop production (Iizumi et al., 2014), none have investigated how these anomalies evolve over 
the course of a multi-year ENSO life-cycle. And yet the expected progression of production anomalies from year to year provides vital information for managing global food stocks and for using international trade as a means of coping with weather-induced production shocks. In our analysis we therefore quantify the magnitude and timing of Pan-American crop production anomalies forced by ENSO life-cycles.

The final question we address in our analysis is how increasing crop production may affect ENSO-induced production variability. In the last 15 years the global harvested area has again begun expanding following nearly two decades of remaining static (Grassini et al., 2013). While part of the increase is attributable to an expansion of physical cultivated area, the majority is due to increases in crop harvesting frequency on already cultivated land (Ray and Foley, 2013). To understand the impact that increasing crop-harvesting frequency has had on ENSO teleconnections, we analyze the shift from single to double cropping that has occurred recently in Brazil. We choose to use this case study - e.g. the increase of 'safrinha' maize in Brazil because not only has it transformed maize production in Brazil, but also because it represents one realization of what Ray and Foley (2013) estimate to be a widespread potential for increasing crop harvesting frequency in Central and South America as a means of increasing production. The results of this section are important for understanding how the correlated risks posed by ENSO - as described in the first half of the analysis - are changing with increasing production.

\section{Data}

In this paper we focus on Pan-American production anomalies for wheat, maize and soybeans. Crop statistics for the United States for 1949-2013 were downloaded from the United States Department of Agriculture, National Agricultural Statistics Service (http://quickstats.nass.usda.gov/, accessed August 6 2015). For Argentina, crop statistics were available for 1969 - 2010 from the Integrated Agricultural Information System (SIIA; http://www.siia.gov.ar/). Crop production data in Brazil were available from 1977 - 2014, and were downloaded from the Brazilian Companhia Nacional de Abastecimento (CONAB; http://www.conab.gov.br/index.php). Wheat yield data for Canada from 1950 to 2012 was downloaded from the CANSIM database, provided by Statistics Canada (http://www5.statcan.gc.ca/cansim). Maize production data from 1950 - 2008 in Mexico was 
downloaded from the INEGI Information Databank

(http://www3.inegi.org.mx/sistemas/biinegi/).

To calculate potential evapotranspiration $\left(\mathrm{ET}_{0}\right)$ we use the Sheffield et al. (2006) monthly $1^{\circ} \times 1^{\mathrm{o}}$ gridded dataset of pressure, humidity, air temperature, minimum temperature, maximum temperature and wind speed. In the soil water balance we initialize soil moisture using estimates from the Noah land surface model, then use monthly precipitation data from the Global Precipitation Climatology Centre (GPCC; Schneider et al., 2011) and soil water holding capacity data from the Global Gridded Surfaces of Selected Soil Characteristics (IGBP-DIS) database (Global Soil Data Task Group, 2000). We use monthly $1^{\circ} \times 1^{\circ}$ estimates of soil moisture from the Noah land surface model version 3.3 in the Global Land Data Assimilation System (GLDAS) version 2. The Noah model is a 1-D simulation of the exchange of water and energy between the soil, vegetation canopy and atmosphere and is forced by estimates of the observed atmosphere state. It uses the static MODIS-based land cover classification (Hansen et al., 2000) and leaf area index derived from MODIS and AVHRR measurements (time-series when available, climatology otherwise; Rodell et al., 2004). We use monthly sea surface temperature (SST) anomaly data from the $2^{\circ} \times 2^{\circ}$ Extended Reconstructed Sea Surface Temperature version $3 \mathrm{~b}$ (ERSSTv3b, Smith et al., 2008). El Niño and La Niña events were selected using the Oceanic Niño index, which is a three-month running mean of SST anomalies in the Niño 3.4 region (http://www.cpc.ncep.noaa.gov/products/analysis_monitoring/ensostuff/ensoyears_ERSSTv3b.s html).

\section{Methods}

\subsection{ENSO ensemble construction}

An ensemble of El Niño and La Niña events was constructed from years in which the mean SST anomaly amplitude during October, November and December, as measured by the Oceanic Niño Index, exceeded 1/2 standard deviation. The Oceanic Niño Index is a three month

running mean of SST anomalies in the Niño 3.4 region, which are calculated as deviations from a 30-year centered monthly climatology. This threshold corresponds to an absolute departure in SSTs of just under $0.5^{\circ} \mathrm{C}$. Following identification of the events, the calendar years corresponding to the event, prior to the event and following the event were used to construct a 
composite ENSO 'life-cycle'. The calendar years for the ensembles will hereafter be referred to as EN -1, EN 0 and EN +1 for the El Niño events, and as $\mathrm{LN}-1, \mathrm{LN} 0$, and $\mathrm{LN}+1$ for the $\mathrm{La}$ Niña events. Years were not allowed to be double counted as EN 0 or LN 0 in one event and EN $-1, \mathrm{LN}-1, \mathrm{EN}+1$ or $\mathrm{LN}+1$ in another event.

\subsection{Yield anomalies}

Expected yields (YldEXst,yr) were calculated by state/province using a Gaussian filter -- which has an effect similar to that of a running mean -- with a kernel density of three years. The trends represent non-climate factors, such as technological advances. Deviations from these trends (Yldst,yr - YldExst,yr) are the absolute yield anomalies, which are converted to percent anomalies relative to expected yield:

$$
\Delta \mathrm{Yld}_{\mathrm{st}, \mathrm{yr}}=\frac{\mathrm{Yld}_{\mathrm{st}, \mathrm{yr}}-\mathrm{YldEX}_{\mathrm{st}, \mathrm{yr}}}{\mathrm{YldEx}_{\mathrm{st}, \mathrm{yr}}}
$$

This method is similar to that used by Iizumi et al. (2014). We then aggregate the yield anomalies into distributions during each phase of the ENSO life-cycle and use a two-tailed t-test to identify distributions that are different $(\mathrm{p}<0.1)$ from a distribution around zero. Yield anomalies were relatively insensitive to the choice of using a Gaussian filter or a five-year running mean to calculate expected yields.

\subsection{Pan-American production anomalies}

While total production anomalies are useful for estimating the magnitude of a crop failure, management decisions that affect planted area make it difficult to directly calculate climaterelated anomalies from production data. We therefore use yield anomalies and static harvested areas (averaged over 2007-2012) to calculate equivalent modern day production anomalies as a percent of total Pan-American production. State yield anomalies are converted to production anomalies by multiplying by the fixed harvested area in a state (HAst). These state-by-year production anomalies are then summed and scaled by the expected country-wide production $\left(\operatorname{PrEx}_{\mathrm{c}, \mathrm{yr}}\right)$ to get percent production anomalies for each country in each year $\left(\Delta \operatorname{Pr}_{\mathrm{c}, \mathrm{yr}}\right)$ :

$$
P r_{s t, y r}-\operatorname{PrEx} x_{s t, y r}=\left(Y l d_{s t, y r}-Y l d E x_{s t, y r}\right) * H A_{s t}
$$




$$
\begin{aligned}
\operatorname{PrEx}_{s t, y r} & =\sum_{s t}^{c} \text { YldEx }_{s t, y r} * H A_{s t} \\
\Delta P r_{c, y r} & =\frac{1}{\operatorname{PrEx_{c,yr}}} \sum_{s t}^{c}\left(P r_{s t, y r}-\operatorname{Pr} E x_{s t, y r}\right)
\end{aligned}
$$

Where $\sum_{s t}^{c}(*)$ indicates the sum over all states in a given country. Finally, the percent production anomalies relative to total production within each country are converted to percent anomalies relative to present-day Pan-American production $\left(\Delta \mathrm{Pr}_{\mathrm{yr}}\right)$ : using the relative production of each country (averaged from 2007-2012).

$$
\Delta \operatorname{Pr}_{y r}=\sum_{c}^{P A}\left(\frac{P r_{c}}{P r_{P A}} * \Delta \operatorname{Pr}_{c, y r}\right)
$$

Where $\operatorname{Pr}_{c}$ is the production of a country, $P r_{P A}$ is Pan-American production, and $\Delta \operatorname{Pr}_{c, y r}$ is the percent production anomaly for a country in a given year. Using time-varying yield anomalies but static harvested areas to calculate production anomalies minimizes the problem of conflating changes in management or technology with climate-driven production anomalies. However, the results presented in this paper are qualitatively the same if production anomalies are calculated using harvested area that is not held constant, but allowed to change by year (see SI Figs 4-6).

\subsection{Isolating the influence of ENSO}

Although ENSO has a significant influence on the climate of North and South America, its influence is not omnipresent. Even in areas in which ENSO reliably influences the climate, crop management or crop water requirements may mediate whether ENSO has a significant influence on crop yields. We therefore need to identify the states/regions in which ENSO significantly affects production. Yield anomalies forced by ENSO were identified using two independent methods. The first was to use a Spearman's rank correlation coefficient to identify the states/regions in which the Oceanic Niño Index was significantly $(\mathrm{p}<0.1)$ correlated with state/province yield anomalies (see Figure 1). To account for serial correlation in the data, significance was evaluated following the methods of Ebisuzaki (1997): the ENSO time series was bootstrapped 1000 times via phase randomization, each realization was correlated with yield anomalies, then these correlation coefficients were rank-ordered to determine confidence 
intervals. For a detailed description of the physical teleconnections that lead to the observed ENSO-yield correlations of Figure 1, see Anderson et al. (2016).

While correlated states were identified using the Oceanic Niño Index, we later present maps of correlations with SSTs in the tropical Pacific. In doing so each grid point constitutes an individual statistical test, so we control the false discovery rate by following the methods of Wilks (2016), which includes a correction for spatially correlated data. A grid point must meet both the significance criteria to be considered significant.

In the second method we calculate the Empirical Orthogonal Functions (EOFs) of a matrix containing vectors of state production anomalies from 1980 - 2012 as a percent of Pan-American production. Each EOF is then related to tropical Pacific SST anomalies to determine its relation with ENSO. By using production anomalies, the EOF analysis preferentially selects modes of variability in major producing states rather than states that contribute little to overall production. The EOF analysis allows us to consider variability in the system as a whole without losing information by aggregating state-level data into a single Pan-America time series. This is important when isolating a signal across many states because it incorporates information about the ways in which the yields of states vary together due to a large-scale forcing, such as ENSO. We use the variance explained by each ENSO-related EOF to estimate the fraction of total production variability attributable to ENSO.

\subsection{Soil Water Content (SWC)}

To analyze the effects of different cropping cycles on ENSO-induced variability in Brazil, we calculate a simple soil water balance as an indicator of water stress. To do so, we first calculate reference evapotranspiration ( $\mathrm{ET}_{0}$; also referred to as 'potential evapotranspiration') using the FAO Penman-Monteith equation:

$$
E T_{0}=\frac{0.408 * \Delta *\left(R_{n}-\mathrm{G}\right)+\gamma * \frac{900}{T+273} *\left(e_{s}-e_{a}\right)}{\Delta+\gamma *\left(1+0.34 * u_{2}\right)}
$$


where $R_{n}$ is net radiation, $\mathrm{G}$ is soil heat flux, $\mathrm{T}$ is mean air temperature at $2 \mathrm{~m}, u_{2}$ is wind speed at $2 \mathrm{~m}, e_{s}$ is saturation vapor pressur, $e_{a}$ is actual vapor pressure, $\Delta$ is the slope of the vapor pressure curve and $\gamma$ is the psychrometric constant. Windspeed was interpolated from 10m down to $2 \mathrm{~m}$ assuming an exponential decay to the surface following equation 47 of Allen et al. (1998). All other variables were calculated following the guidelines for monthly data outlined in Allen et al. (1998).

The reference evapotranspiration was converted to evapotranspiration over cropland using a series of monthly varying cropping coefficients $(\mathrm{Kc})$. While the reference ET assumes a timeinvariant ground-cover of grassland, the cropping coefficient modifies this to represent evapotranspiration from a seasonally-varying evapotranspiration caused by crop growth.

$$
E T_{c}=K c * E T_{0}
$$

Values for Kc are typically broken into values at planting $\left(K c_{\text {initial }}\right)$, for mature crops $\left(K c_{\text {mid }}\right)$ and just before harvesting $\left(K c_{\text {end }}\right)$. Table 1 indicates the months of planting, flowering and harvest for each crop in Brazil. Table 2 details the Kc values, following from Allen et al. (1998), used for each crop. A uniform $\left(K c_{\text {initial }}\right)$ of 0.1 was used for all crops. Values for months between $K c_{\text {initial }}, K c_{\text {mid }}$ and $K c_{\text {end }}$ were derived by linear interpolation.

Next the evapotranspiration is modified according to an estimate of soil water stress to account for the fraction of water extractable by plants:

$$
\begin{gathered}
E T=f * E T_{c} \\
f=\frac{w}{w^{*}}
\end{gathered}
$$

where $\mathrm{w}$ is the soil moisture, and $w^{*}$ is the plant extractable water capacity. For a given month, if $\mathrm{w}>w^{*}$, then $\mathrm{w}=w^{*}$. The change in soil moisture with time is then calculated as:

$$
\begin{aligned}
\frac{d w}{d t} & =P-E T-R \\
R & =w-w^{*}
\end{aligned}
$$


where $\mathrm{P}$ is precipitation, ET is evapotranspiration over the cropped area, and R is runoff. Although our SWC calculation doesn't include snowmelt or irrigation, which may be important in some regions of the world, we don't expect these to be important for maize or soybeans in Brazil. In 2006, irrigation in Brazil accounted for only $4.95 \%$ and $2.54 \%$ of the total harvested area of maize and soybean, respectively (FAO, 2013a; FAO, 2013b).

\subsection{SWC in different crop rotations during ENSO life-cycles}

In this analysis we investigate two main cropping cycles currently practiced in Brazil. The first cropping cycle represents a rotation of wheat, maize, soybean and winter cover crop over three years. Because this crop rotation is three years long, different parcels of land may be at three different stages of the cycle in any given year. We therefore use three sequences of Kc values to represent each potential stage of the cycle for a given year. These sequences of Kc values are used to calculate SWC, which is then averaged to represent the mean state of soil moisture. The second cropping cycle represents a shorter-season rotation of soybeans and maize in a single year (which we refer to as a 'safrinha cycle'). See the Results section and Figure 9 for a further discussion of these two cropping cycles. Finally, the SWC calculated for each cropping cycle over the complete observational period (1950 - 2010) is composited into El Niño and La Niña life-cycles to estimate how the choice of cropping cycle affects SWC in ENSO years.

\section{Results}

\subsection{ENSO life-cycles and yield anomalies}

The first row of panels in Figure 2 illustrate that during the mean El Niño life-cycle, sea surface temperature (SST) anomalies in the tropical Pacific tend to be slightly negative in the winter prior to peak El Niño (EN -1) and return to a slightly negative state by the following winter (EN 1). La Niñas, on the other hand, develop following El Niños and persist for two winters thereafter (Fig. 1). In the following discussion EN 0 and LN -1 both represent El Niño conditions, while LN 0 and $\mathrm{LN}+1$ denote La Niña conditions. In this analysis we discuss ENSOinduced yield and production anomalies. For a detailed description of the physical mechanisms that link tropical Pacific SST anomalies to yield anomalies of maize, wheat and soybean via flowering-season temperature and precipitation teleconnections, see Anderson et al. (2016). 
We first analyze the distribution of state-level yield anomalies in each country over the course of El Niño and La Niña life-cycles. This analysis is intended to illustrate how the timing and sign of anomalies are distributed during the life-cycle of ENSO. We will later convert these yield anomalies to production anomalies and combine them to estimate total Pan-American production anomalies for each year.

Maize yield anomalies are of mostly the same sign across North and South America during years of peak positive (EN 0, LN -1) and negative (LN 0) SST anomalies (Fig. 2). The most notable exception to this same-sign variability is Brazil, which often shows yield anomalies of an opposite sign to those of the US and Argentina. The split between Argentina and Brazil likely reflects the north-south dipole in precipitation anomalies induced by ENSO during boreal winter (SI Fig. 3; Anderson et al., 2016). The pattern of same-sign variability in the US and Argentina is also clear in the correlated states analysis (Fig. 2).

The influence of ENSO on state-wise soybean yield anomalies is not clear when all states in each country are considered. However, when only states that are significantly correlated with ENSO are included in the analysis, a clear life-cycle of yield anomalies in the US and Argentina emerges (Fig. 3). This life-cycle is a direct reflection of the SST anomalies, including the persistently negative anomalies during both LN0 and LN1 years. Yield anomalies in Mato Grosso, Brazil, are statistically significant but of a modest magnitude, indicating a potential sensitivity to the method of calculating anomalies.

The relation between ENSO and wheat yields in North America is complicated by the presence of both spring and winter wheat. In this analysis we show results only for winter wheat in North America, which accounts for $\sim 72 \%$ of North American wheat. When we later convert these yield anomalies to production anomalies, we use total wheat production (winter + spring) in the denominator to calculate percent production anomalies (see methods). Figures depicting spring wheat anomalies can be found in the supplementary information.

The relation between ENSO and wheat yields in the Americas can be conceptually split into two parts. The first is the same-season teleconnections in South America, in which an El Niño creates 
excess moisture that often leads to an increased probability of disease for wheat crops (Cunha et al., 2001). The second is lagged teleconnections in North America, in which an El Niño increases winter precipitation that then persists via soil moisture into the spring flowering season and increases winter wheat yields (Anderson et al., 2016). These two indirect teleconnections lead to same-sign yield variability in a given year (Fig. 4)

\subsection{Pan-American production anomalies}

We next construct time series of Pan-American production anomalies (see methods), which are binned by phase of the El Niño and La Niña life-cycles, to estimate the magnitude and progression of ENSO-induced anomalies. Here we also include an EOF analysis of PanAmerican production anomalies as an alternative method of estimating the major drivers of production variability.

For maize, production anomalies are on average $\sim 5 \%$ of expected production during EN $0, \mathrm{LN}-1$ and LN 0 years (Fig. 5). Both this binned production anomaly analysis and the correlation with same-season SST anomalies in the tropical Pacific indicate that the first principal component represents a time series of production anomalies related to tropical Pacific SSTs. These production anomalies are consistent in sign and magnitude between the 'all states', the 'correlated states' and PC1 of the EOF analysis. While we might have predicted a priori that ENSO would be the leading mode of the EOF analysis, the extent to which ENSO dominates total Pan-American maize production variability (accounting for $71.9 \%$ of the variance) is remarkable.

Pan-American soybean production anomalies demonstrate similar coherence at large scales, although the timing of the anomalies is different from that of maize (Fig. 6). Soybean production anomalies are greatest during peak El Niño (EN 0 and LN -1 in Fig.6) years and during secondyear La Niñas (LN 1), when hemispheric yield anomalies are additive (see Fig.3. for yield anomalies). During the transition from El Niño to La Niña (LN 0), the flowering season in North America occurs during positive SST anomalies while the flowering season in South America occurs during negative SST anomalies, which leads to offsetting yield anomalies in LN 0 years (see Fig. 3). Production variability associated with EOF1 (30.0\% of total production variability) 
is related to the tropical Pacific and resembles that of the correlated states and of the all states analyses. As with maize, the pattern of production anomalies is robust across all analyses. The coherence in these anomalies is noteworthy provided the hemispheric and seasonal separation between North American and South American flowering seasons.

Similar to the yield anomaly analysis, the Pan-American wheat production anomaly time series can be conceptually separated into lagged teleconnections and same-season teleconnections. The time series of production anomalies induced by lagged teleconnections is significantly correlated with previous-season tropical Pacific SST anomalies (Fig. 7). This relationship appears in the analysis of all states, the correlated states, and PC1 (48.9\% of the variance) as an increase in yield in the year following an El Niño (EN 1, LN 0), although there is no visible decrease in yield in the year following a La Niña (LN 1; see Fig. 7). The production anomalies induced by same-season teleconnections are represented in PC3 (8.0\% of total production variance), which is negatively correlated with same-season winter Pacific SST anomalies. The production anomalies of PC3 are of the same sign as PC1, but of a smaller magnitude. When taken together, the analyses in Figure 7 support the idea that the lagged ENSO teleconnection in North America is the dominant driver of Pan-American wheat production variability.

\subsection{Production intensification and ENSO teleconnections}

The vulnerability of global agriculture to climate-induced risks is not static in time. It evolves with the location, timing and intensity of regional cropping patterns. From 2002-2011, the harvested area of staple crops (cereal, oil, sugar, fiber, tuber and root crops) increased globally at a rate of 9.8 million hectares per year (Grassini et al., 2013). But not all of this increase in harvested area was a physical increase in the area under cultivation. From 2000-2011, the rate of expansion in harvested area attributable to an increased crop harvesting frequency was four times greater than the rate attributable to an increase in physical area (Ray and Foley, 2013). In fact, the crop harvesting frequency across much of Central and South America is estimated to be well below the maximum potential crop harvesting frequency (see Fig. 4 of Ray and Foley, 2013), implying a potential for production increases across much of the region. As such, it's relevant to ask how changes in crop harvesting frequency will impact ENSO-induced Pan-American production variability. 


\subsubsection{Increasing crop harvesting frequency affects yield teleconnections}

To demonstrate how ENSO teleconnection are affected by increasing crop harvesting frequency, we will consider the example of changing cropping patterns in Brazil. Until the late 1990s, most maize in Brazil has been grown in a cropping rotation of wheat, maize, soybean and a winter cover crop. Although the time of planting can be variable, rotations consist of roughly four crops and two cover crops planted in the span of three years. In recent years, however, a cropping cycle of maize, soybean and a winter cover crop has become common. Each crop is grown in a shorter season such that six crops and three cover crops are harvested in three years. This new cropping cycle, in which the maize is referred to as 'safrinha' -- meaning 'short season' -- maize, changes the timing and duration of the growing season for both soybean and maize. We will refer to this cropping cycle (i.e. soybeans -- safrinha maize) as a safrinha cropping cycle. Figure 8 illustrates how the rapid rise in total production of safrinha maize drastically altered the agricultural production landscape of Brazil. Safrinha maize, which was a minor source of production in the year 2000, became the dominant source of maize production in Brazil by 2015. Table 2 lists the simplified representation of planting, flowering, and harvest months of each crop in each cropping cycle used in this analysis. Note that all analyses for Brazil in the previous sections were based on statistics of total (safrinha + traditional) maize production, but in this section we differentiate between the two. The second and third rows of Figure 8 plot state-wise yield anomalies of total maize and of safrinha maize during El Niño and La Niña.

To estimate what effect changing cropping cycles has had on yield anomalies, we analyze the percent yield anomalies of each type of maize during El Niño (EN 0) and La Niña (LN 0) in the major safrinha maize producing states (Mato Grosso, Paraná, Mato Grosso do Sul, São Paulo and Minas Gerais). In these states, ENSO appears to influence safrinha maize but not maize grown in the traditional cropping cycle (third row, Fig. 8). Safrinha maize yield anomalies are significantly positive during El Niño years and negative during La Niña years. This distribution of state-wise,

ENSO-induced, yield anomalies is opposite that of traditional maize when all states in Brazil are considered (second row, Fig. 8). The difference in the response of traditional maize to ENSO in the 'all states' compared to the 'major safrinha states' analysis is a reflection of the growing location of each crop, consistent with the dipole in the ENSO teleconnections in Brazil (Figure 1 and SI Fig. 3). The more numerous states of the Northeast dominate the state-wise yield 
distribution but account for relatively little of the total production, while further south maize yield anomalies are of the same sign as those in southeast South America (Cunha, 2001).

However, these differences in growing location cannot explain why ENSO affects safrinha maize yields but not early maize yields in the major safrinha producing states.

The observed difference in ENSO-induced variability may be related to (1) a change in the timing of the planting season and therefore a change in the ENSO teleconnections during that season, (2) a change in moisture demand resulting from increased cropping intensity, or (3) a difference in management of the two crops. To test the climate-related hypotheses, we use a soil water balance with two imposed cropping cycle evapotranspirations (ETs), one relating to each cropping cycle.

\subsubsection{Increasing crop harvesting frequency affects soil water content}

It's worthwhile to compare the seasonally varying evapotranspiration caused by crops with the climatology of and ENSO teleconnections to precipitation. Figure 9 illustrates the timing of seasonal precipitation and the Kc curves used to modify the potential evapotranspiration $\left(\mathrm{ET}_{0}\right)$ and calculate the soil water content (SWC). Moving from a traditional cropping season to a safrinha cropping cycle moves the crop flowering season away from the months of peak climatological precipitation towards the drier shoulder months. In terms of ENSO teleconnections, El Niño years result in wetter conditions throughout the growing season, while La Niña conditions result in drier conditions. There is a notable exception for La Niña in March, which coincides with the start of the safrinha maize season, although precipitation is below climatology for the remainder of the season (Fig. 9).

We also show correlations between anomalies of soil water content (SWC') calculated using $\mathrm{ET}_{0}$, and 0-40 cm soil moisture anomalies from the Noah land surface model in Figure 9. The good correlations over southeast South America, where land cover is often similar to the grassland type assumed in the $\mathrm{ET}_{0}$ calculation, indicates that our simple SWC calculation matches the soil moisture estimates from a more complex land surface model (Fig. 9). We further test the reliability of the SWC calculated using the Kc curves to modify ET 0 by comparing correlations between state crop yield anomalies and state-averaged percent SWC anomalies (Tables 3-5), 
using analogous correlations between yield anomalies and Noah percent soil moisture anomalies as a benchmark. Our SWC anomalies correlate with yields as well as Noah soil moisture anomalies in nearly all cases. However, for the soybean correlations in Table 5 we were forced to assume soybeans were grown during the traditional cropping cycle -- and therefore to correlate them with SWC anomalies from the traditional growing season -- because no separate statistics for safrinha-cycle soybeans were available. This simplification makes comparison of yield anomalies and SWC anomalies difficult because both safrinha-cycle and traditional-cycle soybean yield anomalies contribute to the reported statistics.

We decompose the SWC anomalies into two parts: (1) differences in the mean soil water content $(\overline{S W C})$ between the safrinha-cycle seasons and the traditional seasons, which reflects a combination of increased evaporative demand and changes in the growing season climate, and (2) changes in the average departure from that mean (SWC') during a particular phase of ENSO, which reflects the differences in seasonal ENSO teleconnections. For EN 0 years, for example:

$$
\begin{aligned}
\Delta \overline{S W C} & =\overline{S W C}_{s a f}-\overline{S W C}_{t r d} \\
\Delta \mathrm{SWC}_{E N 0}^{\prime} & =\frac{1}{N_{E N 0}} \sum_{i y}^{N_{E N 0}}\left(\mathrm{SWC}_{\text {saf }, i y}^{\prime}-\mathrm{SWC}_{t r d, i y}^{\prime}\right)
\end{aligned}
$$

where the subscript 'saf' indicates the SWC dataset created using ETo altered by the safrinha Kc curve, and 'trd' indicates the SWC dataset created using $\mathrm{ET}_{0}$ altered by the traditional Kc curve. NENo indicates the number of EN 0 years in the composite and the subscript iy indicates a particular year in the composite.

Figure 10 demonstrates that for much of Brazil, shifting the maize growing season from the traditional season (Oct - May) to the later, shorter safrinha season (Feb - Jun) leads to considerable climatological mean drying during maize flowering months, which may also be seen in Figure 9. This drying can, in part, explain why the safrinha cropping cycle is most widespread in the state of Mato Grosso, which experiences only minimally drier conditions during safrinha flowering months compared to the traditional maize flowering months. To the south and east, however, there is a considerable decrease in SWC in the states of Paraná, Mato Grosso do Sul, São Paulo and Goiás, which collectively account for $\sim 55 \%$ of safrinha maize production. We can expect that a greater average soil water stress may leave crops more 
vulnerable to precipitation failures, which is consistent with the hypothesis that the greater safrinha maize yield anomalies observed in Fig. 8 are related to ENSO.

Changing from a traditional maize cropping cycle to a safrinha cropping cycle will not only cause the SWC to be lower on average during flowering months, but also to be more variable during ENSO life-cycles (because of stronger ENSO teleconnections; compare SWC anomalies between traditional and safrinha seasons in Fig. 10). These results further support the idea that switching from a traditional cropping cycle to a safrinha cropping cycle will increase ENSOforced yield variability in ENSO years.

The consequences of moving from a traditional cropping cycle to a safrinha cropping cycle are much the same for soybean as they were for maize. There is a net climatological drying during the flowering months on average in Southern Brazil, and an increase in SWC variability during ENSO years (Fig. 11). However, while the safrinha maize flowering months are shifted later in the year relative to the traditional growing season, the soybean flowering months are shifted earlier in the year towards strong ENSO precipitation teleconnections (Fig. 9). The increase in strength of teleconnections is apparent in Figure 11, and implies that shifting to a safrinha cropping cycle may intensify the ENSO-forced yield anomalies of soybeans in addition to maize.

Another way to visualize the changes in SWC is to take a box-average (see box in Figs. 10 and 11) chosen to cover a portion of the states of Paraná, Mato Grosso do Sul, São Paulo and Goiás previously discussed. Figures 12 and 13 show the SWC for each cropping cycle over the course of an El Niño and La Niña life-cycle for maize (Fig. 12) and soybean (Fig. 13). The decrease in precipitation during La Niña (LN 0, LN 1) leads to more severe soil water stress during both traditional and safrinha cropping cycles. The increased precipitation during El Niño (EN 0 and LN -1) occurs most strongly in the early portion of the rainy season and so leads to the largest increase in SWC during the safrinha cycle soybean flowering months. These results reiterate the conclusions from Figures 10 and 11: that switching to a safrinha cropping cycle may increase both maize and soybean yield variability as a result of moving the flowering seasons into months with strong ENSO teleconnections. 
These results are consistent with Cohen et al. (2016), who demonstrate that farmers practicing double cropping - soybeans followed by safrinha maize - reduce cropping frequency in response to climate shocks, such as ENSO. Farmers choose to grow a longer, single season crop of soybeans in years with climate shocks rather than try to fit in a double crop, which, as we have demonstrated, would negatively affect the yield of both crops. Such behavior complicates the relationship between ENSO and crop yields, but intensifies influence of ENSO on total PanAmerican production. Our results reinforce a growing focus on the need to understand how climate shocks may influence harvested areas (Iizumi and Ramankutty, 2015).

\section{Conclusions}

In this analysis we demonstrated that despite occurring in different hemispheres and seasons, local ENSO-induced yield anomalies in major producing parts of North and South America particularly the United States and southeast South America -- are often of the same sign for a given year, which means ENSO poses a correlated risk to crop production in the Americas. ENSO-induced production anomalies account for $\sim 72 \%, 30 \%$ and $57 \%$ of Pan-American maize, soybean and wheat production variability, respectively. ENSO-induced variability is greatest for maize, with median anomalies of $\sim 5 \%$ relative to expected production.

The implications of our analysis for food security are threefold: 1. ENSO poses a risk to agriculture that is correlated across hemispheres. 2. ENSO-induced production anomalies follow a multi-year evolution as a result of ENSO life-cycles. Poor Pan-American harvests of maize and soybean attributable to La Niña tend to follow years with above expected production attributable to El Niño, a fact that could inform policies relating to food stocks and food security. 3. Increases in the frequency of crop harvesting can increase ENSO-induced anomalies due to the timing and location of the double-cropping flowering seasons as compared to the single-cropping flowering season, as has been the case in Brazil.

ENSO life-cycles force a clear multi-year evolution of both Pan-American maize and soybean production anomalies. Wheat production anomalies are also influenced by ENSO, but demonstrate greater variability within a given year of an ENSO life-cycle. Maize production anomalies are greatest during El Niños (EN 0) and first-year La Niñas (LN 0), while soybean 
production anomalies are greatest during El Niños and second-year La Niñas (LN +1), when soybean yield anomalies are of the same sign in North and South America. During LN 0 years soybean yield anomalies in North America are often offset by those in South America.

In addition to characterizing present-day ENSO-induced production variability, we analyzed how changing cropping patterns have influenced the vulnerability of agriculture to ENSO. We found that increasing the number of cropping cycles per year in areas with strong ENSO teleconnections has led to greater ENSO-induced production variability. Fitting two cropping cycles into the space of a single rainy season makes growing conditions more vulnerable to ENSO-induced precipitation deficits, particularly when it moves flowering season months towards months with stronger ENSO teleconnections. We demonstrated this using crop statistics and calculations of soil water content for safrinha maize in Brazil, which shows increased production variability attributable to ENSO when compared with traditional maize grown in the same areas. In fact, switching to a safrinha cropping cycle (soybeans - safrinha maize) may have an impact on production variability of both soybeans and maize because precipitation deficits forced by La Niña are greatest in the beginning of the rainy season during safrinha-cycle soybean flowering months. However, there are no separate crop statistics available to confirm this.

While observed increases in crop harvesting frequency have exacerbated ENSO-induced anomalies, knowledge of the spatial structure of ENSO teleconnections could instead be leveraged to offset anomalies by intensifying production in regions with offsetting ENSO teleconnections. For example, while an increase in maize production in southeast South America will intensify ENSO-induced anomalies because ENSO teleconnections in the region are of the same sign as in North America (see Fig. 1), an increase in maize production in northeast Brazil will offset production anomalies in North America and southeast South America.

As the single most prominent source of crop production variability, it is crucial that we continue to characterize correlations in the spatial and temporal risks posed by ENSO. Understanding the globally-coherent teleconnections of ENSO is particularly relevant for countries that rely on trade to mitigate weather-induced production shocks. And in the future, as we increase global crop production, it's important to consider how we are changing the vulnerability of our 
agricultural system to ENSO-induced temperature and precipitation anomalies. Our analysis considers only three crops in North and South America, but these considerations are applicable globally.

Acknowledgments: This material is based upon work supported by the National Science Foundation Graduate Research Fellowship under Grant No. DGE-11-44155. RS acknowledges support from NSF award AGS-1401400. We would like to thank an anonymous reviewer for his/her constructive comments. NCEP Reanalysis and GPCC data was provided by the NOAA/OAR/ESRL PSD from their website at http://www.esrl.noaa.gov/psd/ . Soil moisture data used in this study was archived and distributed by the Goddard Earth Sciences (GES) Data and Information Services Center (DISC). 


\section{References}

Alexander, M. A., I. Blade', M. Newman, J. R. Lanzante, N.-C. Lau, and J. D. Scott, 2002: The atmospheric bridge: The influence of enso teleconnections on air-sea interaction over the global oceans. Journal of Climate, 15 (16), 2205-2231.

Allen, R. G., L. S. Pereira, D. Raes, M. Smith, and Coauthors, 1998: Crop evapotranspirationguidelines for computing crop water requirements-fao irrigation and drainage paper 56. FAO, Rome, 300 (9), D05 109.

Anderson, W., Seager, R., Baethgen, W. and Cane, M., 2016: Life cycles of agriculturally relevant ENSO teleconnections in North and South America. Int. J. Climatol.. doi:10.1002/joc.4916

Berlato, M. A., and D. C. Fontana, 2001: Impacts of el niño and la niña on agricultural production in southern brazil and the use of climate forecasts in agriculture. Applications of climate forecasting for better decisionmaking processes in agriculture. Passo Fundo: Embrapa Trigo, $217-241$.

Cohn, A.S., VanWey, L.K., Spera, S.A. and Mustard, J.F., 2016: Cropping frequency and area response to climate variability can exceed yield response. Nature Climate Change.

Cunha, G., G. Dalmago, and V. Estefanel, 2001: El nino southern oscillation influences on wheat crop in brazil. Wheat in a Global Environment, Springer, 445-450.

Cunha, G. R., 2001: El Niño southern oscillation and climate forecasts applied to crops management southern brazil. Cunha, GR; Haas, JC; Berlato, MA Applications of climate forecasting for better decision-making processes in agriculture. Passo Fundo: Embrapa Trigo, 181-201.

Ebisuzaki, W., 1997: A method to estimate the statistical significance of a correlation when the data are serially correlated. Journal of Climate, 10 (9), 2147-2153.

FAO, 2009: High food prices: the food security crisis of 2007/2008 and recent food price increases - facts and lessons.

FAO, 2010: Food outlook, global market analysis.

FAO, FAOSTAT, 2013a: "Statistical Yearbook 2013: World Food and Agriculture." FAO Food Agric. Organziation UN Rome Italy. Available at: http://www.fao.org/faostat/en/

FAO, AQUASTAT, 2013b: "AQUASTAT Information system on water in agriculture." Available at: http://www.fao.org/nr/water/aquastat/data/query/index.html.

Ferreyra, R. A., G. P. Podesta', C. D. Messina, D. Letson, J. Dardanelli, E. Guevara, and S. Meira, 2001: A linked-modeling framework to estimate maize production risk associated with enso- related climate variability in argentina. Agricultural and Forest Meteorology, 107 (3), 177-192. 
Foley JA, Ramankutty N, Brauman KA, Cassidy ES, Gerber JS, Johnston M, Mueller ND, O'Connell C, Ray DK, West PC, Balzer C, Bennett EM, Carpenter SR, Hill J, Monfreda C, Polasky S, Rockström J, Sheehan J, Siebert S, Tilman D, Zaks DP: Solutions for a cultivated planet. Nature; 2011 Oct 20;478(7369):337-42

Global Soil Data Task Group, 2000: Global Gridded Surfaces of Selected Soil Characteristics (International Geosphere-Biosphere Programme - Data and Information System). Data set. Available on-line [http://www.daac.ornl.gov] from Oak Ridge National Laboratory Distributed Active Archive Center, Oak Ridge, Tennessee, U.S.A.

Grassini, P., Eskridge, K.M. and Cassman, K.G., 2013. Distinguishing between yield advances and yield plateaus in historical crop production trends. Nature Communications, 4.

Handler, P., 1984: Corn yields in the united states and sea surface temperature anomalies in the equatorial pacific ocean during the period 1868-1982. Agricultural and Forest Meteorology, 31 (1), 25-32.

Hansen, M., R. DeFries, J. R. Townshend, and R. Sohlberg, 2000: Global land cover classification at $1 \mathrm{~km}$ spatial resolution using a classification tree approach. International journal of remote sensing, 21 (6-7), 1331-1364.

Hsieh, W. W., B. Tang, and E. R. Garnett, 1999: Teleconnections between pacific sea surface temperatures and Canadian prairie wheat yield. Agricultural and forest Meteorology, 96 (4), 209-217.

Iizumi, T., J.-J. Luo, A. J. Challinor, G. Sakurai, M. Yokozawa, H. Sakuma, M. E. Brown, and T. Yamagata, 2014: Impacts of el nin o southern oscillation on the global yields of major crops. Nature communications, 5.

Iizumi, Toshichika, and Navin Ramankutty. 2015: "How do weather and climate influence cropping area and intensity?." Global Food Security 4: 46-50.

Izaurralde,R.,N.Rosenberg,R.Brown,D.Legler,M.T.Lo' pez,andR.Srinivasan,1999:Modeled effects of moderate and strong Los Nin os' on crop productivity in North America. Agricultural and Forest Meteorology, 94 (3), 259-268.

López, M. T., C. Izaurralde, N. J. Rosenberg, A. D. B. Gonza'lez, and J. S. Garc' 1a, 2003: Modeling El Nin o southern oscillation climate impact on Mexican agriculture. GEOFISICA INTERNACIONAL-MEXICO-, 42 (3), 331-340.

Mauget, S. A., and D. R. Upchurch, 1999: El Niño and La Niñ a related climate and agricultural impacts over the Great Plains and Midwest. Journal of Production Agriculture, 12 (2), 203-215.

Phillips, J., B. Rajagopalan, M. Cane, and C. Rosenzweig, 1999: The role of ENSO in determining climate and maize yield variability in the U.S. cornbelt. International Journal of Climatology, 19, 877-888, doi:10.1002/(SICI)1097-0088(19990630)19:8<877::AIDJOC406)3.0.CO;2-Q. 
Podesta', G. P., C. D. Messina, M. O. Grondona, and G. O. Magrin, 1999: Associations between grain crop yields in Central-Eastern Argentina and El Nin o-Southern Oscillation. Journal of Applied Meteorology, 38 (10), 1488-1498, doi:10.1175/1520-0450(1999)038〈1488:ABGCYI〉 2.0.CO;2, URL http://dx.doi.org/10.1175/1520-0450(1999)038〈1488:ABGCYI〉 2.0.CO;2.

Ray, D.K. and Foley, J.A., 2013. Increasing global crop harvest frequency: recent trends and future directions. Environmental Research Letters, 8(4), p.044041.

Rodell, M., P. Houser, U. Jambor, J. Gottschalck, and Coauthors, 2004: The global land data assimilation system. Bulletin of the American Meteorological Society, 85 (3), 381.

Schneider, U., A. Becker, P. Finger, A. Meyer-Christoffer, B. Rudolf, and M. Ziese, 2011:

GPCC Full Data Reanalysis Version 6.0 at 1.0 degree: Monthly Land-Surface Precipitation from Rain- Gauges built on GTS-based and Historic Data.

Sheffield, J., G. Goteti, and E. F. Wood, 2006: Development of a 50-year high-resolution global dataset of meteorological forcings for land surface modeling. Journal of Climate, 19 (13), 30883111 .

Smith, T. M., R. W. Reynolds, T. C. Peterson, and J. Lawrimore, 2008: Improvements to noaa's historical merged land-ocean surface temperature analysis (1880-2006). Journal of Climate, 21 (10), 2283-2296.

Trenberth, K. E., G. W. Branstator, D. Karoly, A. Kumar, N.-C. Lau, and C. Ropelewski, 1998: Progress during toga in understanding and modeling global teleconnections associated with tropical sea surface temperatures. Journal of Geophysical Research: Oceans, 103 (C7), 14 29114324.

Wannebo, A., and C. Rosenzweig, 2003: Remote sensing of US cornbelt areas sensitive to the El Niño-Southern Oscillationo-Southern Oscillation. International Journal of Remote Sensing, 24 (10), 2055-2067.

Wilks, D. S., 2016: "the stippling shows statistically significant gridpoints": How research results are routinely overstated and over-interpreted, and what to do about it. Bulletin of the American Meteorological Society, (2016). 

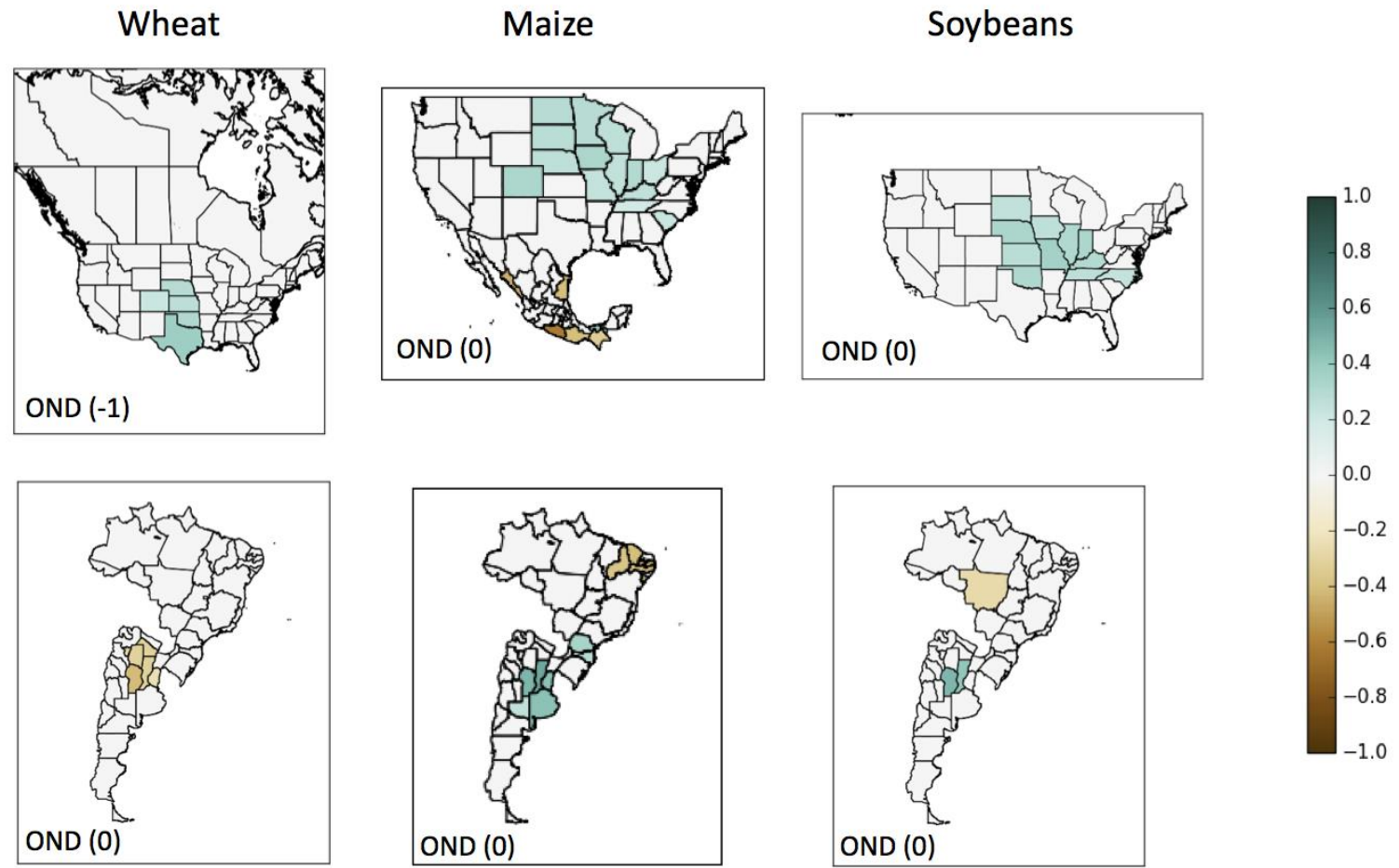

Fig 1. - Spearman's rank correlations between wheat, maize or soybean and the OctoberNovember-December Oceanic Niño Index, which is calculated as the three month running mean of sea surface temperatures in the Niño 3.4 region. Same-season correlations indicated as $\mathrm{OND}(0)$, lagged correlations to the previous season Oceanic Niño Index shown as $\mathrm{OND}(-1)$. Only statistically significant correlations $(\mathrm{p}<0.1)$ are shaded. 
El Niño life-cycle
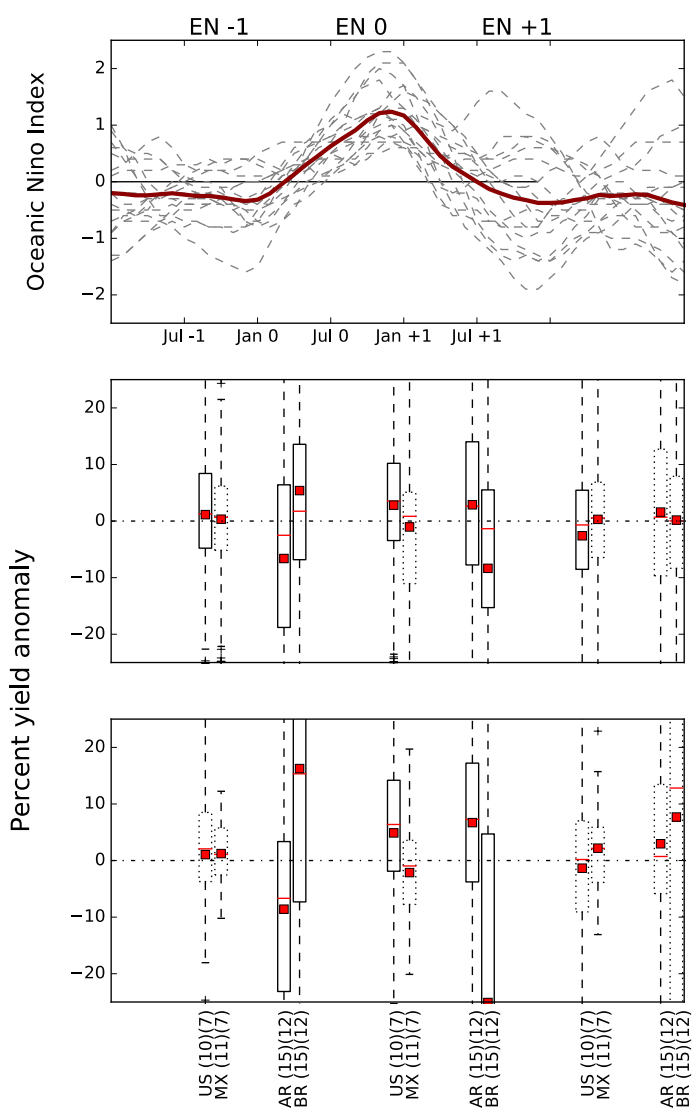

La Niña life-cycle
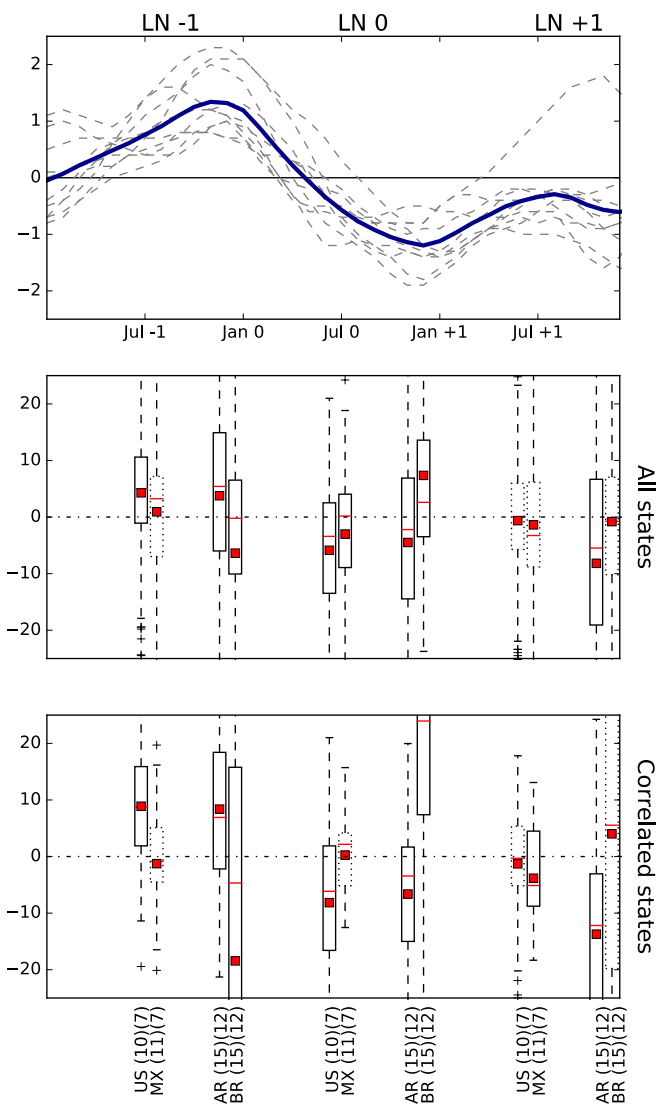

Fig 2. - Distributions of state/province maize yield anomalies for each country. Solid boxes indicate samples that are statistically significant $(\mathrm{p}<0.1)$. Red lines indicate distribution medians and red squares indicate distribution means. Countries are abbreviated on the x-axis (United States (US), Mexico (MX), Argentina (AR) and Brazil (BR)), with the harvest and flowering months shown in parenthesis 
El Niño life-cycle
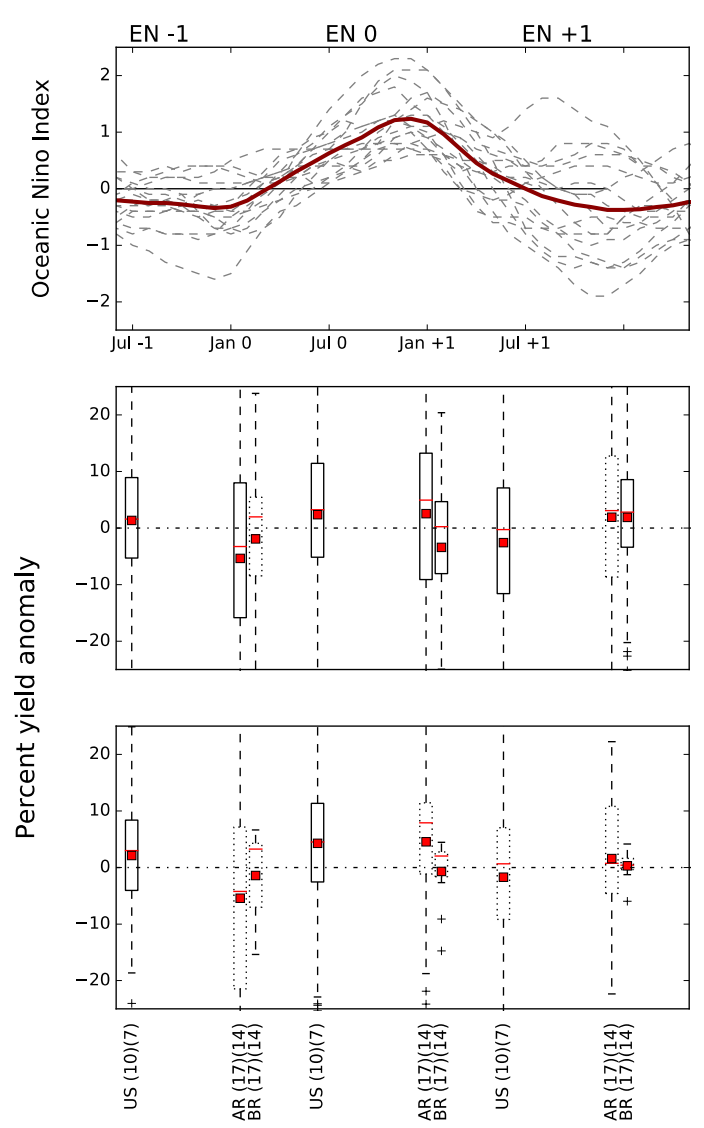

La Niña life-cycle
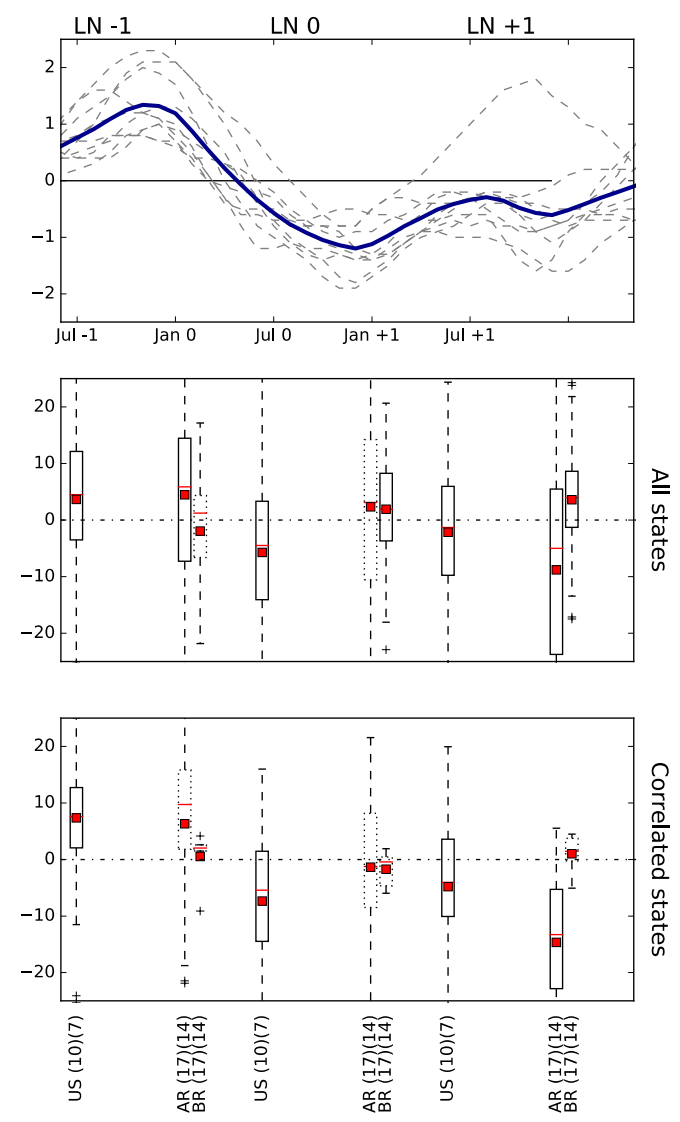

Fig 3. - Distributions of state/province soybean yield anomalies for each country. Solid boxes indicate samples that are statistically significant $(\mathrm{p}<0.1)$. Red lines indicate distribution medians and red squares indicate distribution means. Countries are abbreviated on the $\mathrm{x}$ - axis (United States (US), Argentina (AR) and Brazil (BR)), with the harvest and flowering months shown in parenthesis 

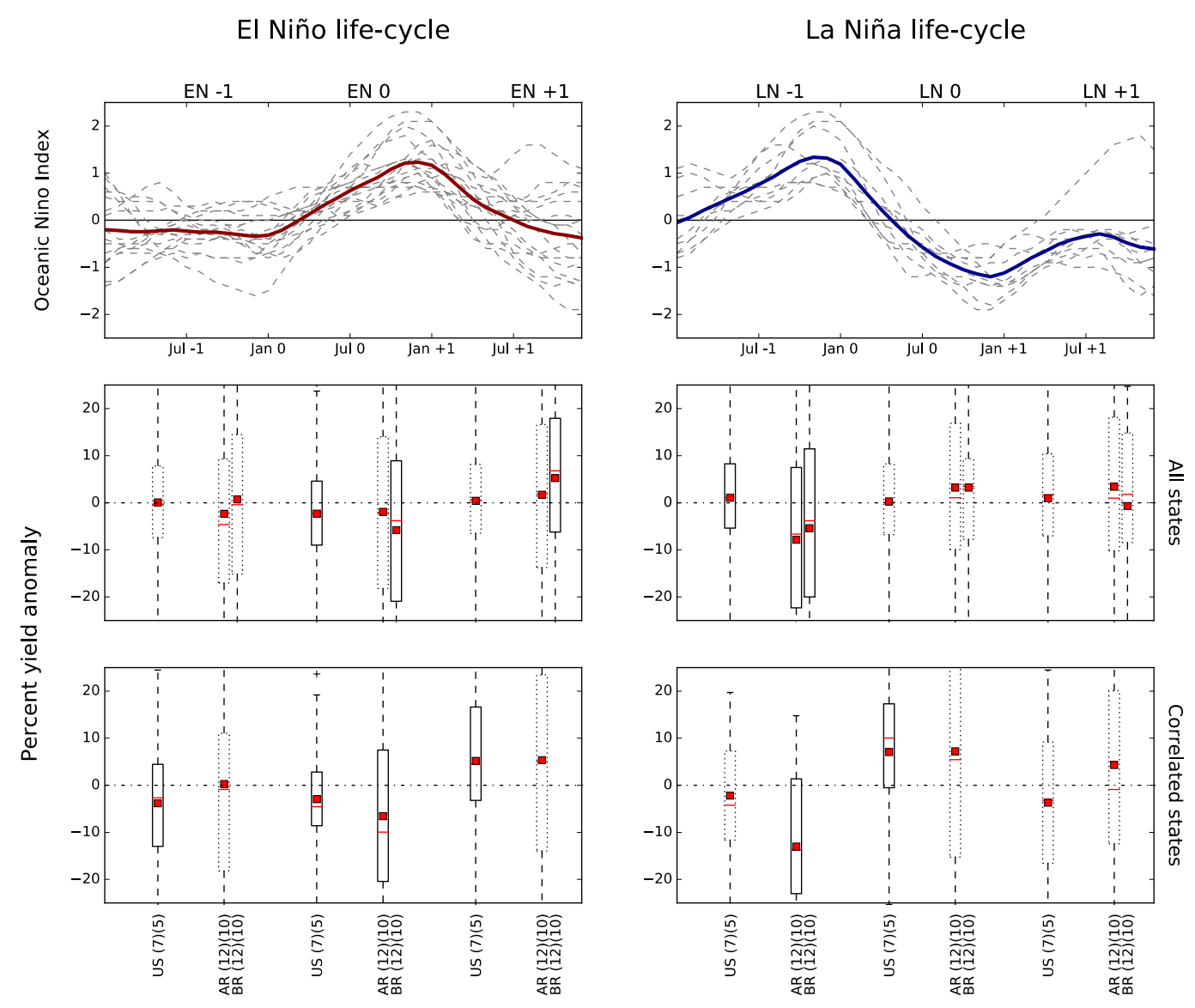

Fig 4. - Distributions of state/province winter wheat yield anomalies for each country. Solid boxes indicate samples that are statistically significant $(\mathrm{p}<0.1)$. Red lines indicate distribution medians and red squares indicate distribution means. Countries are abbreviated on the $\mathrm{x}$ - axis (United States (US), Argentina (AR) and Brazil (BR)), with the harvest and flowering months shown in parenthesis 

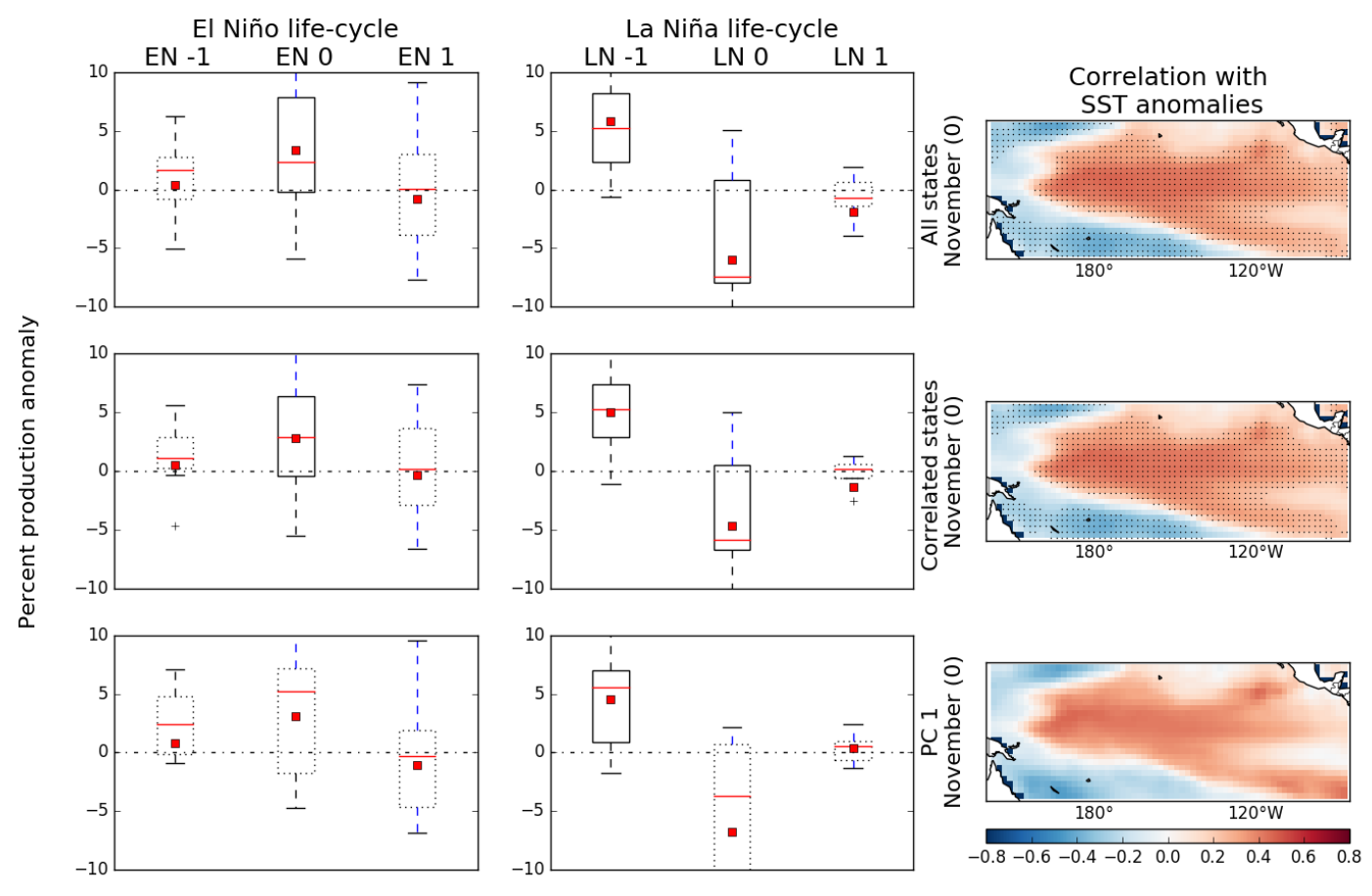

Fig 5. - Maize Pan-American production anomalies. Solid boxes indicate samples that are statistically significant $(\mathrm{p}<0.1)$. Red lines indicate distribution medians and red squares indicate distribution means. Stippling in the SST correlation plots indicates statistically significant $(\mathrm{p}<0.1)$ correlations with December of either the same year (December $(0)$ ) or the previous year (December (-1)). Stippling significance is corrected for serial correlation and accounts for false discovery due to multiple tests (see methods). 

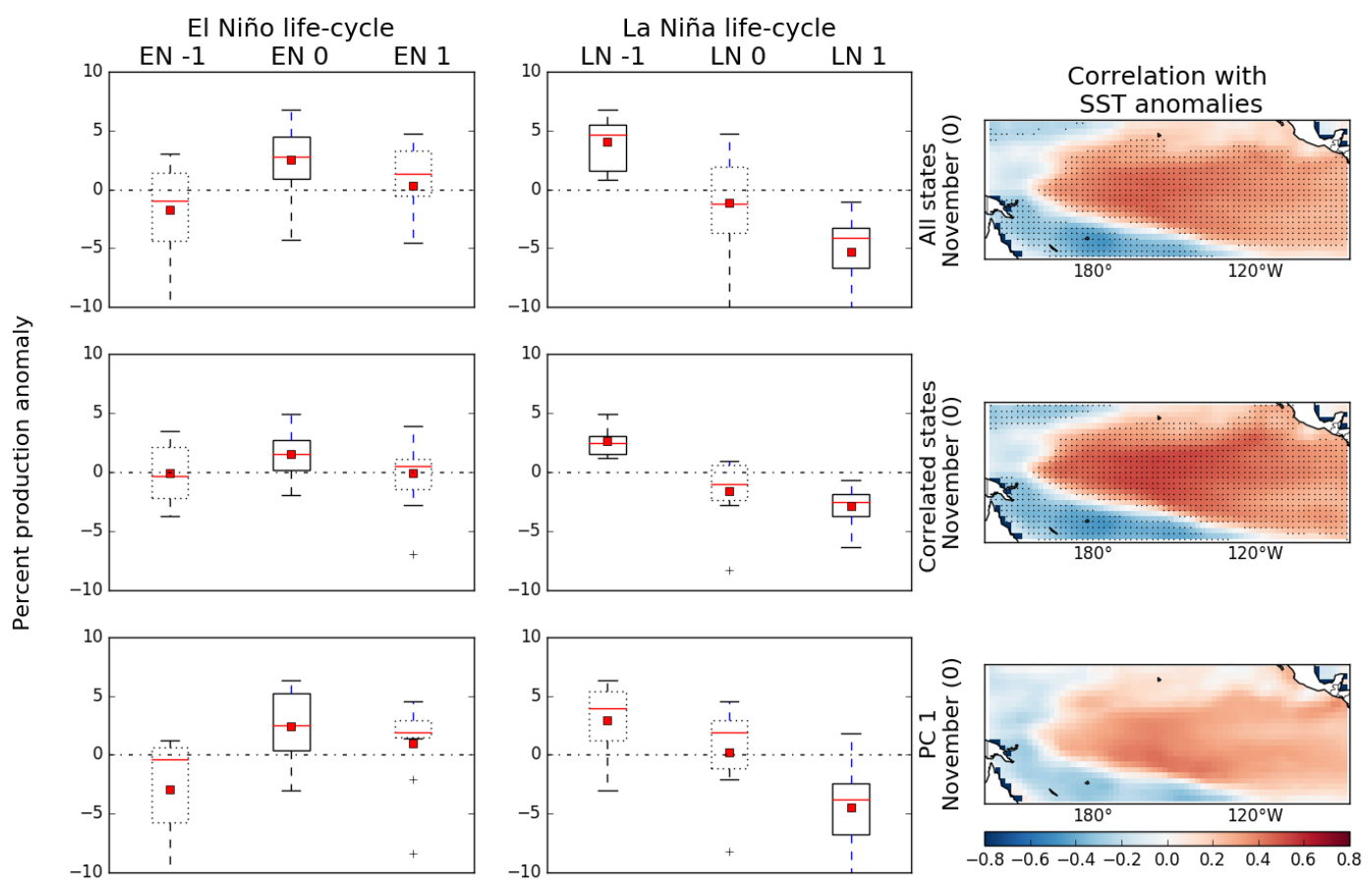

Fig 6. - Soybean Pan-American production anomalies. Solid boxes indicate samples that are statistically significant $(\mathrm{p}<0.1)$. Red lines indicate distribution medians and red squares indicate distribution means. Stippling in the SST correlation plots indicates statistically significant $(\mathrm{p}<0.1)$ correlations with December of either the same year (December (0)) or the previous year (December (-1)). Stippling significance is corrected for serial correlation and accounts for false discovery due to multiple tests (see methods). 

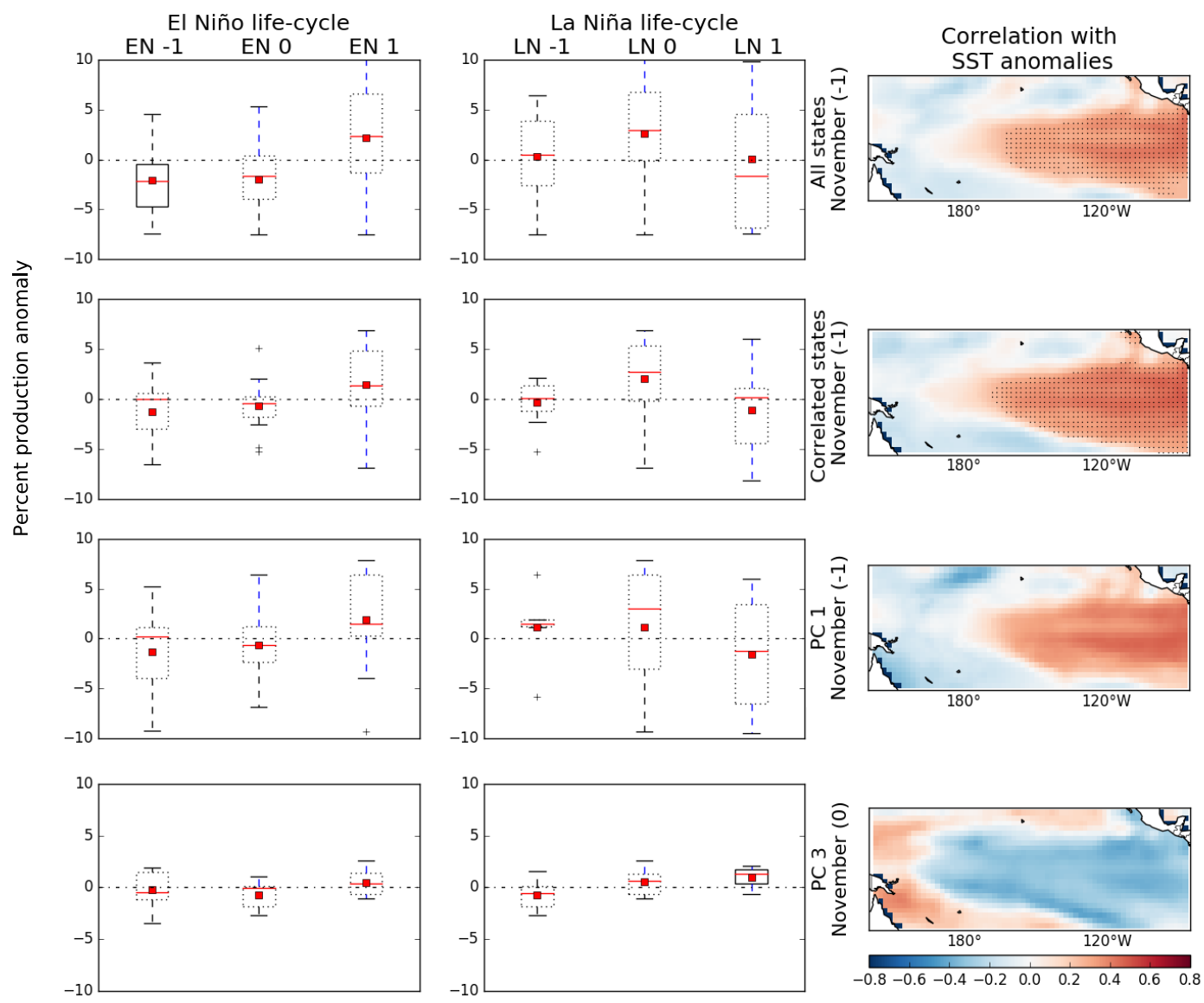

Fig 7. - Winter wheat Pan-American production anomalies. Solid boxes indicate samples that are statistically significant $(\mathrm{p}<0.1)$. Red lines indicate distribution medians and red squares indicate distribution means. Stippling in the SST correlation plots indicates statistically significant $(\mathrm{p}<0.1)$ correlations with December of either the same year (December (0)) or the previous year (December (-1)). Stippling significance is corrected for serial correlation and accounts for false discovery due to multiple tests (see methods). 

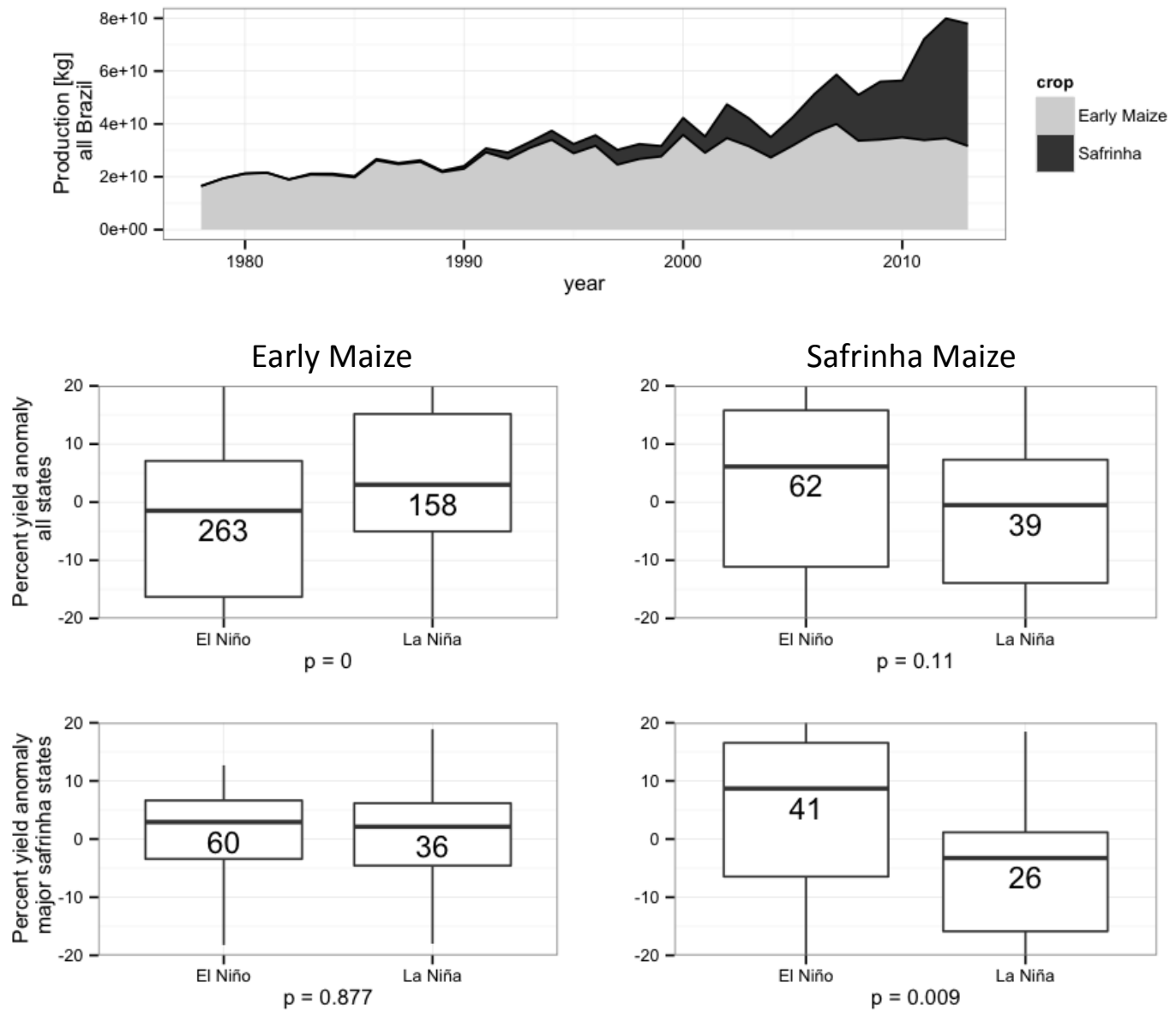

Fig 8. - Maize production in Brazil and distribution of state yields separated by cropping cycle and location. The numbers in each box plot indicate the number of samples (states times years) in that distribution. The p-value below each plot is an indication of the likelihood that El Niño and La Niña distributions are statistically significantly different from one another. 

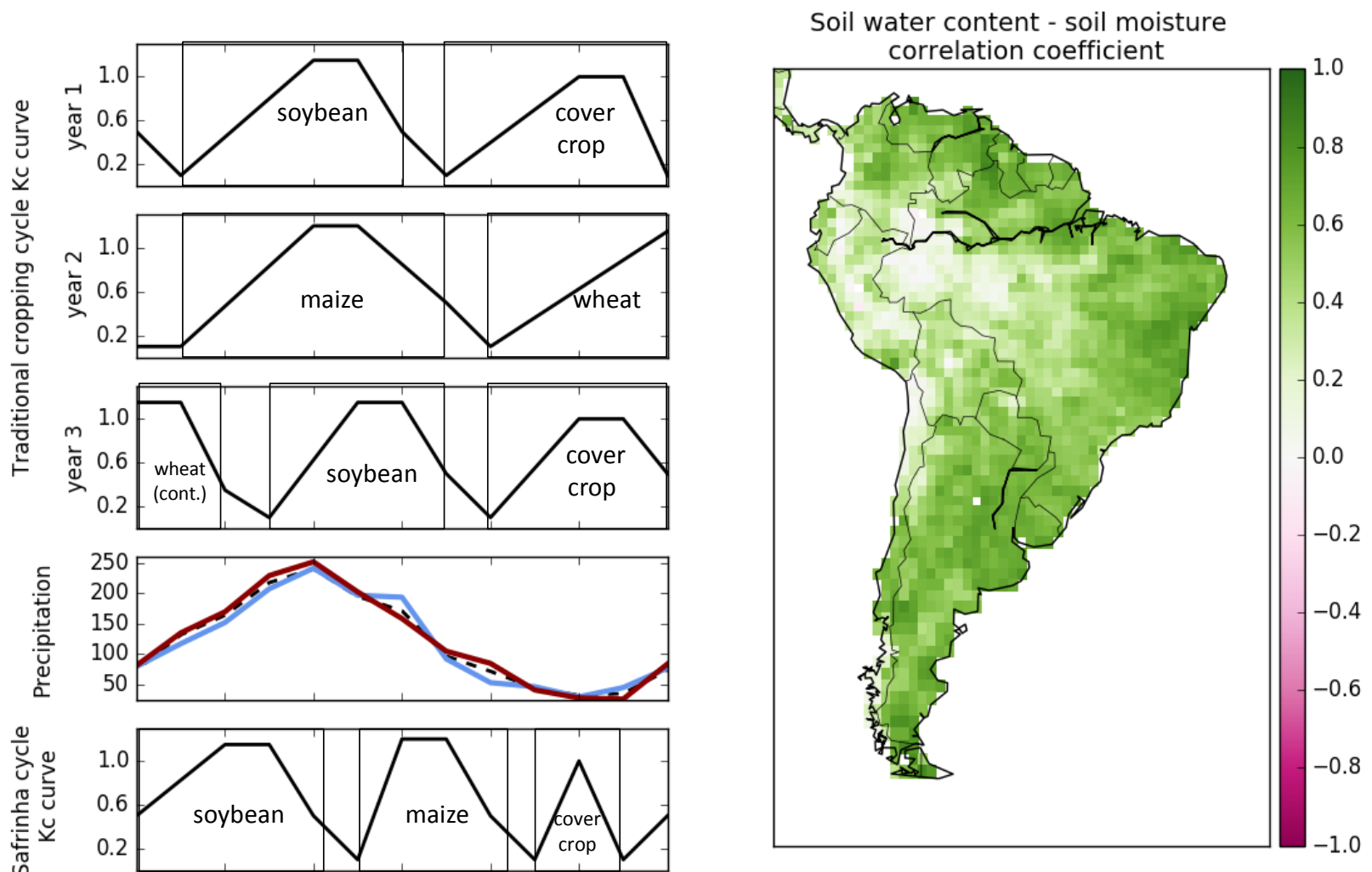

Fig 9. - Reference evapotranspiration (ET) correlation with Noah soil moisture (right), Kc curves used later to modify the reference ET and precipitation (left panels). Black dotted line indicates precipitation climatology, solid red (blue) lines indicate mean precipitation during El Niño (La Niña) years. 


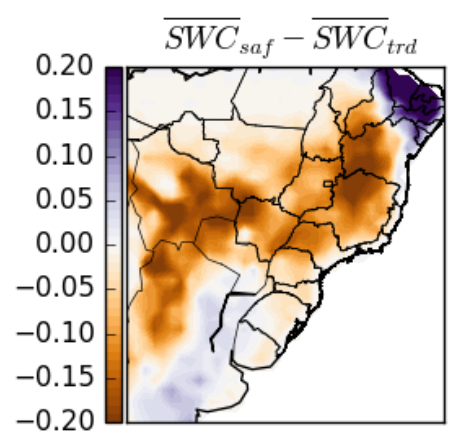

\section{El Niño life-cycle}
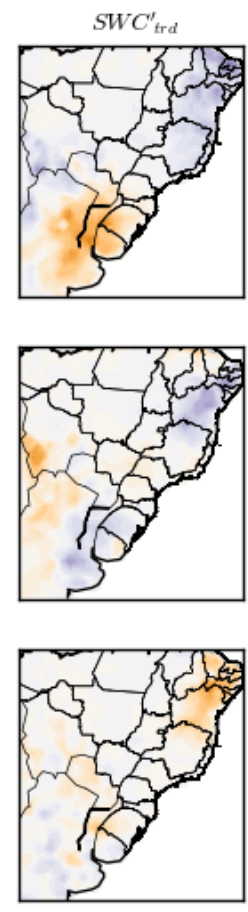
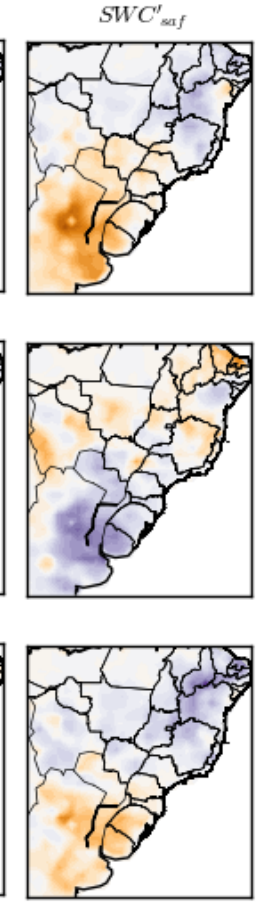

La Niña life-cycle
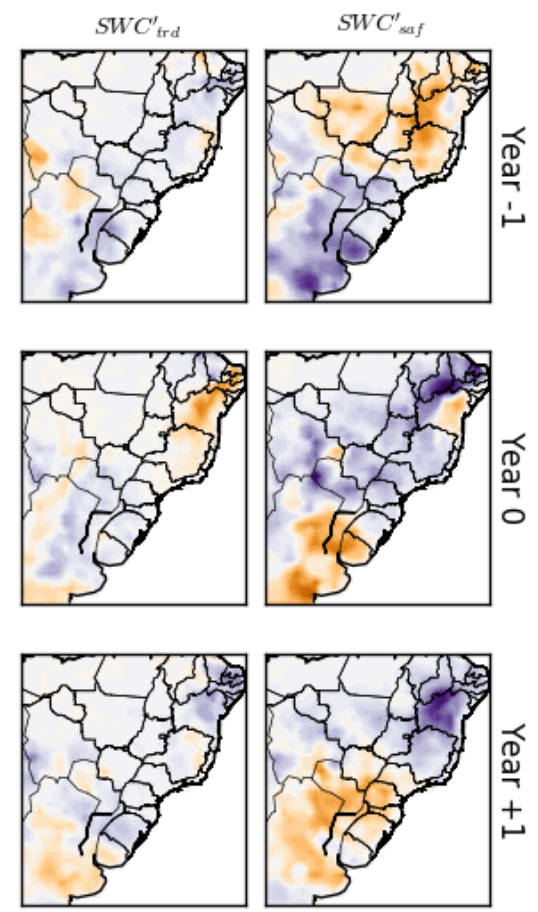

Fig 10. - Differences between soil water content during the traditional $\left(S W C_{t r d}\right)$ and safrinha $\left(S W C_{s a f}\right)$ maize flowering months. Both $S W C_{s a f}$ and $S W C_{t r d}$ is decomposed into mean $(\overline{S W C})$ and anomaly $\left(S W C^{\prime}\right)$ terms as $S W C=\overline{S W C}+S W C^{\prime}$. Mean differences over all years area shown in the top left panel $\overline{S W C}_{s a f}-\overline{S W C}_{t r d}$. Departures from each mean state during El Niño and La Niña life-cycles (ENSO teleconnections) shown in the right four columns $S W C_{s a f}^{\prime}-S W C_{t r d}^{\prime}$. Brazilian states and box average for Fig 12 shown in bottom left panel. 


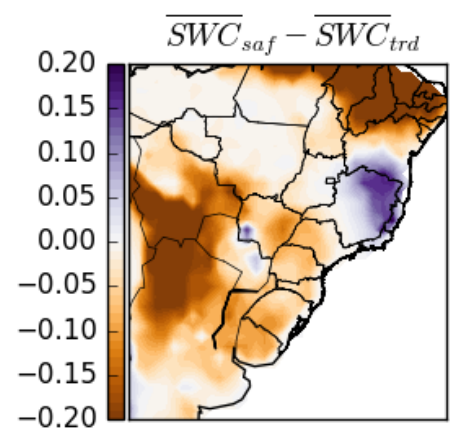

\section{El Niño life-cycle}
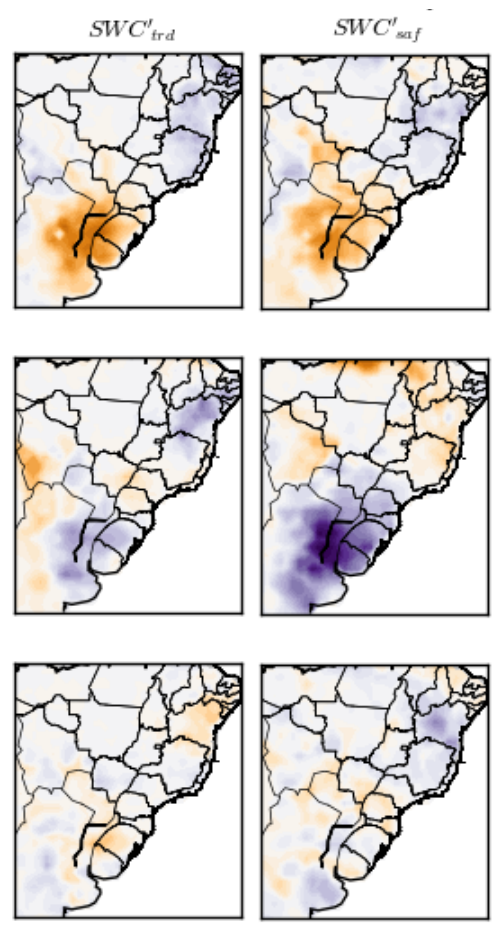

La Niña life-cycle
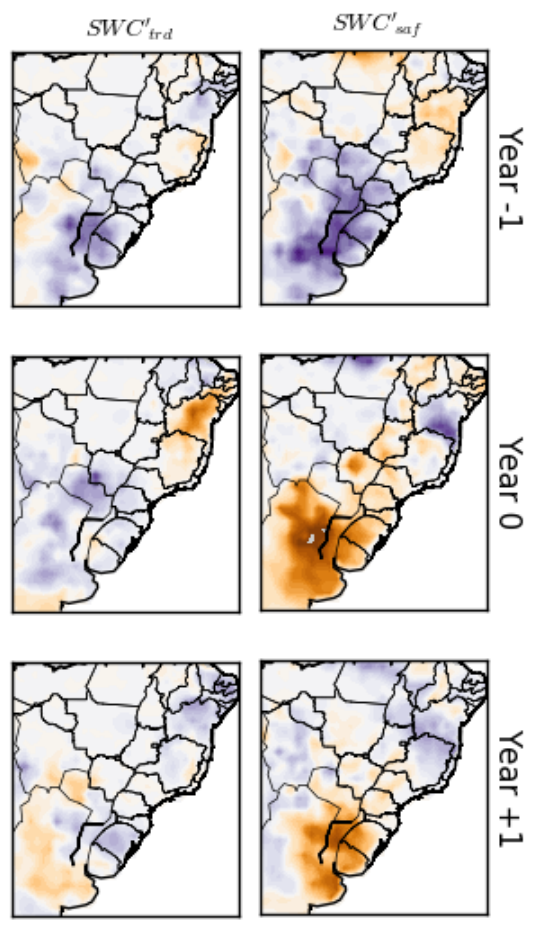

Fig 11. - Differences between soil water content during the traditional $\left(S W C_{t r d}\right)$ and safrinha $\left(S W C_{s a f}\right)$ soybean flowering months. Both $S W C_{s a f}$ and $S W C_{t r d}$ is decomposed into mean $(\overline{S W C})$ and anomaly $\left(S W C^{\prime}\right)$ terms as $S W C=\overline{S W C}+S W C^{\prime}$. Mean differences over all years area shown in the top left panel $\overline{S W C}_{s a f}-\overline{S W C}_{t r d}$. Departures from each mean state during El Niño and La Niña life-cycles (ENSO teleconnections) shown in the right four columns $S W C_{s a f}^{\prime}-S W C_{t r d}^{\prime}$. Brazilian states and box average for Fig 12 shown in bottom left panel. 

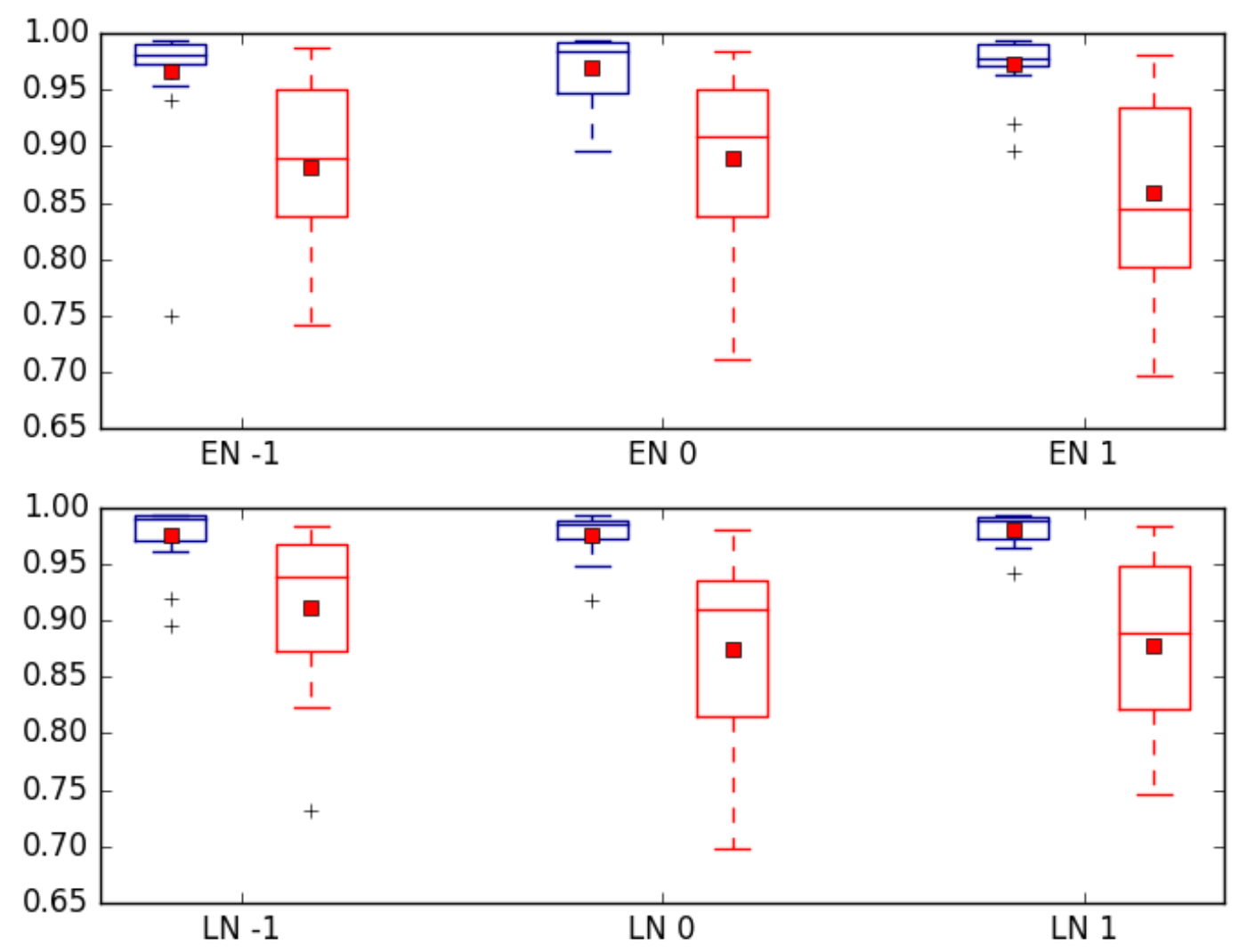

Fig 12. - Soil water content (SWC) over the southern safrinha growing area (Paraná Mato Grosso do Sul, São Paulo and Goiás; box in Figs 10 and 11) during maize flowering months. Blue boxes represent the SWC calculated using the traditional cropping cycle Kc values, orange boxes are the SWC calculated using the safrinha cropping cycle Kc values during an El Niño (top row) and La Niña (bottom row) life-cycle 

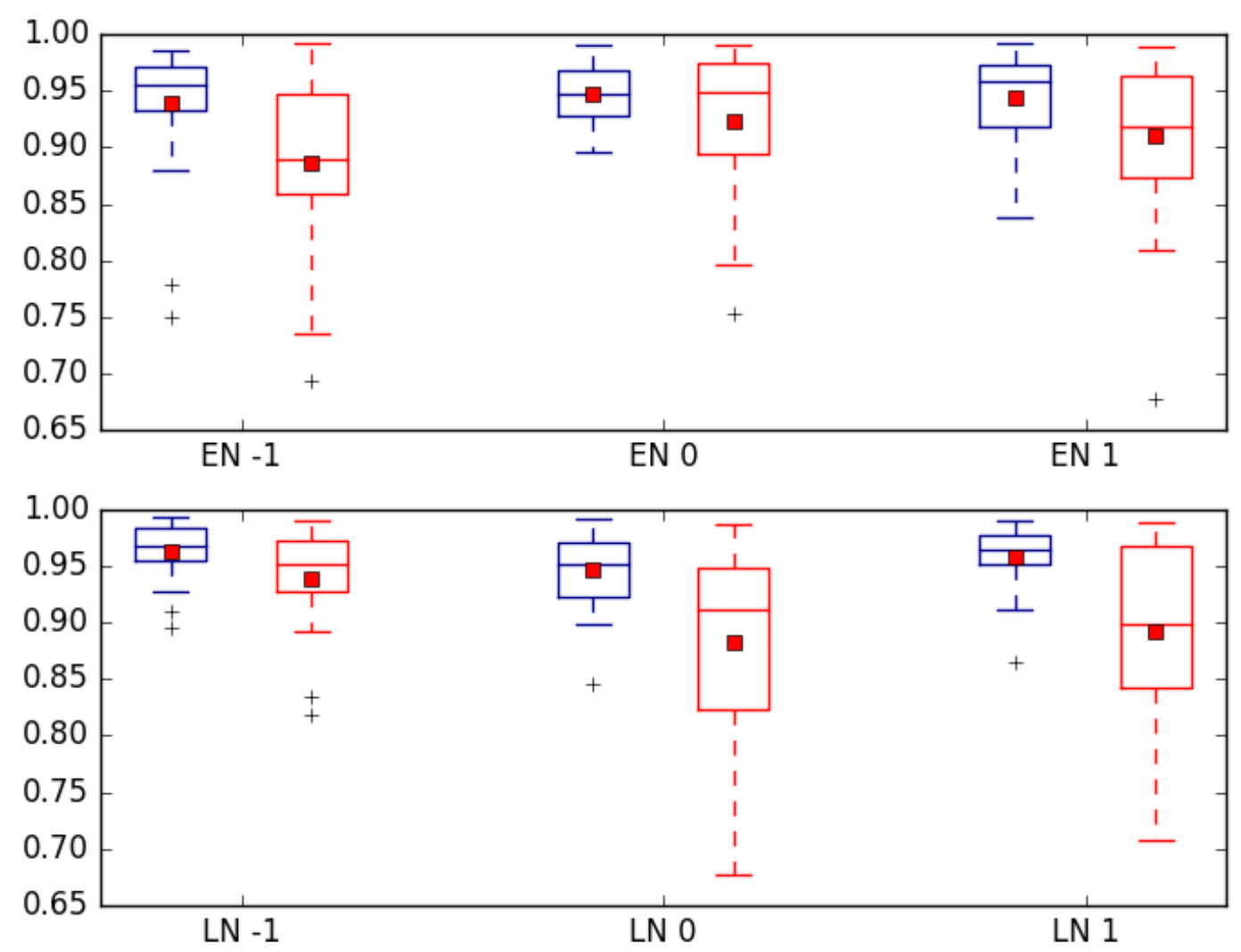

Fig 13 - Soil water content (SWC) over the southern safrinha growing area (Paraná Mato Grosso do Sul, São Paulo and Goiás; box in Figs 10 and 11) during soybean flowering months. Blue boxes represent the SWC calculated using the traditional cropping cycle Kc values, orange boxes are the SWC calculated using the safrinha cropping cycle Kc values during an El Niño (top row) and La Niña (bottom row) life-cycle 
Table 1. - Crop growing seasons in Brazil

\begin{tabular}{|l|l|l|l|l|}
\hline & Plant & Flower start & Flower end & Harvest \\
\hline Wheat & May-June & September & November & December \\
\hline Maize & October & January & March & May \\
\hline Soybean & October & January & March & April \\
\hline Safrinha cycle maize & February & March & April & June \\
\hline Safrinha cycle soybean & September & November & January & February \\
\hline
\end{tabular}

Table 2. - Evapotranspiration Kc parameters

\begin{tabular}{|l|l|l|}
\hline & Kc_mid & Kc_end \\
\hline Wheat & 1.15 & 0.35 \\
\hline Maize & 1.2 & 0.5 \\
\hline Soybean & 1.15 & 0.5 \\
\hline Safrinha cycle maize & 1.2 & 0.5 \\
\hline Safrinha cycle soybean & 1.15 & 0.5 \\
\hline
\end{tabular}

Table 3. - Correlations between safrinha season maize yield anomalies and two metrics of soil stress during the growing season. Soil water content (SWC) is taken to be a percent of soil water holding capacity, soil moisture is taken from 10-40 cm layer of the Noah land surface model. Both quantities are averaged over each state

\begin{tabular}{|l|l|l|l|}
\hline & Noah SM - Safrinha & SWC - Safrinha & Percent of Production \\
\hline MT & 0.27 & 0.59 & 38.39 \\
\hline PR & 0.26 & 0.60 & 26.24 \\
\hline MS & 0.49 & 0.59 & 14.87 \\
\hline GO & 0.53 & 0.46 & 10.24 \\
\hline SP & 0.66 & 0.85 & 4.11 \\
\hline MG & 0.21 & 0.14 & 1.22 \\
\hline RS & - & - & 0 \\
\hline SC & - & - & 0 \\
\hline
\end{tabular}


Table 4. - As in Table 3 but for early season maize yield anomalies in the traditional cropping cycle

\begin{tabular}{|l|l|l|l|}
\hline & Noah SM - Early Maize & SWC - Early Maize & Percent of Production \\
\hline PR & 0.60 & 0.45 & 20.31 \\
\hline MG & 0.20 & 0.33 & 18.48 \\
\hline RS & 0.65 & 0.74 & 14.05 \\
\hline SC & 0.49 & 0.62 & 9.96 \\
\hline SP & 0.40 & 0.56 & 9.96 \\
\hline GO & 0.16 & 0.22 & 9.45 \\
\hline MT & 0.17 & -0.10 & 1.52 \\
\hline MS & 0.47 & 0.39 & 1.25 \\
\hline
\end{tabular}

Table 5. - As in Table 3 but for soybean yield anomalies in the traditional cropping cycle

\begin{tabular}{|l|l|l|l|}
\hline & Noah SM - Soy & SWC - Soy & Percent of Production \\
\hline MT & -0.02 & -0.26 & 29.07 \\
\hline PR & 0.59 & 0.71 & 19.10 \\
\hline RS & 0.61 & 0.81 & 13.99 \\
\hline GO & -0.04 & -0.04 & 11.21 \\
\hline MS & 0.45 & 0.54 & 7.45 \\
\hline MG & 0.14 & 0.33 & 4.32 \\
\hline SP & 0.17 & 0.47 & 2.35 \\
\hline SC & 0.51 & 0.77 & 1.8 \\
\hline
\end{tabular}

